\title{
CARACTERIZAÇÃO MORFOLÓGICA DA BACIA HIDROGRÁFICA DO RIBEIRÃO SANTA BÁRBARA, GOIÁS ${ }^{1}$
}

\author{
Ana Paula Fioreze ${ }^{2}$, Luiz Fernando Coutinho de Oliveira ${ }^{3}$, Alexandre Puglisi Barbosa Franco ${ }^{4}$
}

\begin{abstract}
MORPHOLOGICAL CHARACTERIZATION OF THE SANTA BÁRBARA RIVER WATERSHED, GOIÁS STATE, BRAZIL

A watershed is the place where every water or soil use made upstream reflects downstream. Because of that, it is the best geographic space for water resources management and planning. It is crucial to identify the geographic and topographic characteristics of a watershed, because those aspects affect its hydrological behavior. In this study, the main Santa Bárbara River watershed characteristics were obtained by using a Geographic Information System (GIS), on a 1:100,000 scale digital map, and satellite images. The procedure showed to be appropriate to obtain physiographic characteristics and average rainfall levels in small watersheds.
\end{abstract}

KEY-WORDS: Watershed; average rainfall; Geographic Information System.

\section{INTRODUÇÃO}

Em um cenário de demanda crescente e disponibilidade limitada, afetada pela contaminação das reservas existentes, os recursos hídricos têm constituído questão central no debate sobre desenvolvimento sustentável e sobre a própria vida no planeta. Desta preocupação crescente, resultou o desenvolvimento de uma série de instrumentos para a gestão dos recursos hídricos.

A bacia hidrográfica é a unidade de gestão dos recursos hídricos, definida pela Política Nacional de Recursos Hídricos, por meio da lei $\mathrm{n}^{\circ}$ 9.433, de 08 de janeiro de 1997 (Brasil 2002), uma vez que, em uma bacia hidrográfica, todos os usos da água e do solo existentes à montante refletem-se nas condições de uso e preservação dos recursos hídricos à jusante.

\section{RESUMO}

Bacia hidrográfica é a unidade de gestão dos recursos hídricos, uma vez que, nela, todos os usos da água e do solo existentes à montante refletem-se nas condições de uso e preservação dos recursos hídricos à jusante. As características físicas de uma bacia afetam diretamente seu comportamento hidrológico e seu conhecimento é necessário à adequada gestão dos recursos hídricos. Este estudo procurou obter as principais características físicas que descrevem a bacia hidrográfica do Ribeirão Santa Bárbara, sub-bacia do Rio Paranaíba, ao sul de Goiás, Brasil. Foi empregado um Sistema de Informações Geográficas (SIG) sobre cartas digitalizadas, na escala 1:100.000, e imagens geradas por satélite, o que se mostrou adequado à obtenção das características fisiográficas e precipitações médias em bacias de dimensões reduzidas.

PALAVRAS-CHAVE: Bacia hidrográfica; precipitação média; Sistema de Informações Geográficas.

Para a adequada implementação de instrumentos de gestão dos recursos hídricos, é necessário o conhecimento do comportamento hidrológico dos rios, em especial de suas vazões efluentes. A atual rede hidrometeorológica brasileira contempla as grandes bacias hidrográficas, com áreas superiores a $500 \mathrm{~km}^{2}$, enquanto as pequenas bacias, com áreas de drenagem inferiores a $100 \mathrm{~km}^{2}$, apresentam carência quase total de dados (Silveira et al. 1998). A falta de dados históricos, que permitam o conhecimento do comportamento hidrológico das bacias, no entanto, é uma realidade não somente no Brasil, mas no mundo todo. Segundo Bjerklie et al. (2005), muitos dos pequenos e médios rios do mundo não são monitorados e, além disso, a rede mundial de monitoramento de rios vem diminuindo.

A determinação da disponibilidade hídrica, em uma bacia hidrográfica, envolve condições naturais

1. Trabalho recebido em maio/2008 e aceito para publicação em maio/2010 (n registro: PAT 3931/ DOI: 10.5216/pat.v40i2.3931).

2. Secretaria de Estado do Meio Ambiente e dos Recursos Hídricos de Goiás, Superintendência de Recursos Hídricos,

Goiânia, GO, Brasil.E-mail: anafioreze@semarh.goias.gov.br.

3. Universidade Federal de Lavras, Faculdade de Engenharia Ambiental, Departamento de Engenharia, Lavras, MG, Brasil.

E-mail: coutinho@deg.ufla.br.

4. AGinfo Agricultura de Informação, Piracicaba, SP, Brasil. E-mail: alexandre.aginfo@gmail.com. 
(fatores climáticos e fisiográficos) e a atuação humana. A intensidade, duração e distribuição espaçotemporal da precipitação sobre uma bacia, bem como a evapotranspiração, estão entre os principais fatores climáticos. Os fatores fisiográficos podem ser sintetizados pela área da bacia, forma, distribuição de relevo, tipo de solo e densidade de drenagem, entre outros. A extensão e forma da bacia estão relacionadas com a quantidade de água que ela pode captar. $\mathrm{O}$ relevo e a densidade de drenagem afetam a velocidade de escoamento e a capacidade de infiltração da água no solo (Tucci 2004).

A caracterização física de uma bacia hidrográfica é de grande importância no estudo de seu comportamento hidrológico e, ainda, no desenvolvimento e aplicação de equações de regionalização de informações hidrológicas. Villela \& Mattos (1975) afirmam que há uma estreita correspondência entre as características físicas e o regime hidrológico, o que possibilita que, ao estabelecerem-se estas relações, variáveis hidrológicas sejam determinadas indiretamente, em outros locais desprovidos de informações. As principais variáveis empregadas para o ajuste e aplicação de equações de regionalização, que permitam esta transferência de informações, incluem as características físicas das bacias hidrográficas, como a área de drenagem, comprimento do rio principal, densidade de drenagem, declividade da bacia e coeficiente de compacidade.

Os valores dessas características são, normalmente, obtidos utilizando-se um Sistema de Informações Geográficas (SIG). Para Svetlichnyi \& Svetlichnaya (2001), a tecnologia SIG pode ser utilizada na modelagem do escoamento superficial de uma bacia hidrográfica e outros processos associados, como arraste de solo e transporte de poluentes, nas formas dissolvida e absorvida.

Este estudo teve como objetivos a caracterização fisiográfica e a obtenção da precipitação anual média e do ano hidrológico, na bacia hidrográfica do Ribeirão Santa Bárbara, em Goiás, empregando-se um Sistema de Informações Geográficas (SIG).

\section{MATERIAL E MÉTODOS}

O estudo foi desenvolvido na área da bacia hidrográfica do Ribeirão Santa Bárbara, localizada entre as coordenadas $17^{\circ} 45^{\prime}$ e $18^{\circ} 15^{\prime}$ de latitude Sul e $49^{\circ} 36^{\prime}$ e $50^{\circ} 03^{\prime}$ de longitude Oeste, na região centro-sul goiana, pertencente à bacia do Rio dos
Bois, que, por sua vez, pertence à bacia hidrográfica do Rio Paranaíba. A área da bacia inclui parte dos municípios de Vicentinópolis, Joviânia, Goiatuba e Bom Jesus de Goiás. O clima da região, segundo a classificação de Köppen, é tropical quente e úmido (Aw). A temperatura média anual é de, aproximadamente, $22^{\circ} \mathrm{C}$ e a mínima apresenta valor médio de $18^{\circ} \mathrm{C}$ (Martins 2003).

As características físicas da bacia foram obtidas pelo emprego de um Sistema de Informações Geográficas (SIG), TNT mips (map image processing system), versão 6.8, da Microimages Inc., Nebraska, EUA. Foram utilizadas ferramentas específicas que trabalham com as características topográficas e fornecem recursos para a geração dos mapas de altimetria (hipsometria), declividade das bacias hidrográficas inseridas na área de interesse e do fluxo de enxurrada, com as respectivas linhas divisórias. A base de dados empregada constituiu-se de cartas digitalizadas, disponibilizadas pelo Instituto Brasileiro de Geografia e Estatística (IBGE), na escala de 1:100.000. Para verificar a precisão das cartas, especialmente a presença e localização dos cursos de água, foram sobrepostas a elas imagens provenientes dos sensores a bordo do satélite Landsat 7, obtidas em agosto de 2002, formadas pelas bandas 5,4 e 3, em composição R, G, B. As imagens foram importadas e georreferenciadas no TNT mips, no módulo "Georeference", a partir de uma extensa malha de pontos de controle de campo, coletados com GPS topográfico, na precisão de $30 \mathrm{~cm}$, em $90 \%$ dos pontos, e $40 \mathrm{~cm}$, nos $10 \%$ restantes, coletados entre 1999 e 2007, cobrindo, praticamente, toda a cena do Landsat utilizada. A avaliação da precisão, aferida pelo módulo específico no TNT mips, apontou um erro máximo de $27 \mathrm{~m} \mathrm{e}$ erro mínimo de 5,3 m, na cena completa do Landsat $(180 \mathrm{~km} \times 180 \mathrm{~km})$.

Foram adicionadas às cartas as curvas de nível equidistantes de $50 \mathrm{~m}$, obtidas a partir de uma combinação de processos. Foi realizada a interpolação topográfica dos dados gerados pela NASA (2000), SRTM (Shuttle Radar Topography Mission), com resolução de $90 \mathrm{~m}$, a partir de uma rede de triangulação irregular, utilizando-se as linhas de quebra de relevo e as de definição de talvegues (breaklines), apoiadas nas cartas do IBGE (1:100.000 e distância vertical de $40 \mathrm{~m}$ ). A partir da rede de triangulação, foi gerado um mapa de isolinhas de nível, com distância vertical de $40 \mathrm{~m}$. Este mapa foi editado no módulo de edição de vetores do TNT mips, para ajuste das falhas comuns 
encontradas nos dados originais e para a suavização das linhas interpoladas. Após o ajuste, foi feita outra interpolação topográfica, para obtenção do mapa raster de resolução de $25 \mathrm{~m}$, retificado e suavizado. O mapa raster foi interpolado topograficamente, novamente, para obtenção do mapa final de isolinhas de nível, com distância vertical de $50 \mathrm{~m}$.

A área de drenagem da bacia foi delimitada a partir da observação das curvas de nível. Após delimitação, foram obtidas, diretamente no SIG, as seguintes características físicas da bacia hidrográfica do Ribeirão Santa Bárbara: área de drenagem, perímetro da bacia, comprimento do curso de água principal, extensão total das drenagens e comprimento do talvegue. Além disso, foram obtidas as altitudes máxima e mínima, cotas e extensões das curvas de nível dentro da bacia e as áreas subentendidas por elas.

A partir das informações obtidas no SIG, as demais características físicas da bacia estudada foram determinadas, conforme proposto por Villela \& Mattos (1975):

- Coeficiente de compacidade: o coeficiente de compacidade é um dos parâmetros que refletem a forma da bacia. Este coeficiente é um número adimensional, que indica a relação entre o perímetro da bacia e o perímetro de um círculo de área igual à da bacia, obtido por

$$
K c=0,28 \frac{P}{\sqrt{A}},
$$

em que $P$ e $A$ são, respectivamente, o perímetro, em $\mathrm{km}$, e a área da bacia hidrográfica, em $\mathrm{km}^{2}$;

- Fator de forma: o fator de forma é, também, um dos parâmetros que refletem a forma da bacia, dado pela relação entre a largura média e o comprimento axial da bacia. $\mathrm{O}$ fator de forma é obtido por

$$
K f=\frac{A}{L^{2}},
$$

onde $A$ é a área da bacia hidrográfica, em $\mathrm{km}^{2}$, e $L$ o comprimento axial da bacia hidrográfica, em $\mathrm{km}$. O coeficiente de compacidade $(K c)$ e o fator de forma $(K f)$ são características que refletem a forma da bacia e indicam a tendência à ocorrência de enchentes. O coeficiente de compacidade compara a forma da bacia com o círculo, cujo $K c$ seria igual a um. Quanto mais irregular a bacia, maior seu $K c$ e menor a tendência a enchentes. $O$ fator de forma é dado pela relação entre a largura média e o comprimento axial da bacia. Uma bacia estreita e longa, com $K f$ baixo, é menos sujeita a enchentes, porque há menos possibilidade de ocorrência de chuvas intensas, cobrindo, simultaneamente, toda sua extensão (Villela \& Mattos 1975);

- Densidade de drenagem: a densidade de drenagem é a razão entre o comprimento total dos cursos de água, em uma bacia hidrográfica, e a sua área e indica se a bacia é bem ou mal drenada. A densidade de drenagem é dada por

$$
D d=\frac{\ell}{A},
$$

em que $\ell$ é a extensão total dos cursos de água, em $\mathrm{km}, \mathrm{e} A$ a área da bacia hidrográfica, em $\mathrm{km}^{2}$;

- Extensão média do escoamento superficial: a extensão média do escoamento superficial representa a distância entre os escoamentos, ou seja, a distância média que a precipitação pluviométrica percorreria sobre o terreno da bacia, até um curso de água em linha reta. Seu valor é obtido por

$$
l=\frac{A}{4 \ell},
$$

onde $A$ é a área da bacia hidrográfica, $\mathrm{em} \mathrm{km}^{2}$, e $\ell$ a extensão total dos cursos de água, em $\mathrm{km}$;

- Sinuosidade do curso principal: a sinuosidade do curso de água principal é a relação entre seu comprimento total e a distância que percorreria em uma linha reta, da nascente à foz, obtida por

$$
\operatorname{Sin}=\frac{L r}{L t},
$$

em que $L r$ é a extensão total do rio principal, em km, e $L t$ o comprimento do talvegue, em $\mathrm{km}$;

- Declividade média da bacia: a declividade média da bacia é calculada a partir da extensão e diferença de nível entre curvas subsequentes, divididas pela área total da bacia, ou seja,

$$
I=\frac{\sum h \times L c n}{A},
$$

onde $h$ é a equidistância entre duas curvas de nível subsequentes, em m; Lcn o comprimento das curvas de nível compreendidas na bacia, em m; e $A$ a área total da bacia, em $\mathrm{m}^{2}$;

- Elevação média: a elevação média da bacia corresponde à média das elevações, em relação ao nível do mar, ponderadas pela relação entre a área entre duas curvas de nível e a área total da bacia, conforme a equação

$$
E=\frac{\sum h_{0} \times a}{A},
$$


em que $E$ é a elevação média da bacia, em $\mathrm{m} ; h_{0}$ a elevação da curva de nível, em relação ao nível do mar, em m; $a$ a área correspondente à curva de nível, em $\mathrm{km}^{2}$; e $A$ a área total da bacia, em km²;

- Curva hipsométrica: a curva hipsométrica é a representação gráfica do relevo de uma bacia, representando a variação da sua elevação. É determinada e traçada a partir do conhecimento da porcentagem da área de drenagem acima de cada cota. Para isso, é preciso conhecer a área subentendida por cada uma das curvas de nível identificadas na bacia;

- Declividade do álveo: a declividade do álveo é uma das formas de descrever o perfil do curso de água principal, obtida dividindo-se a diferença de elevação entre a nascente e a foz pela extensão horizontal do curso de água, entre estes dois pontos, pela equação

$$
S_{1}=\frac{H}{L t},
$$

onde $S_{l}$ é a declividade, em $\mathrm{m} \mathrm{m}^{-1} ; H$ a diferença de cota entre os pontos que definem o início e o fim do curso de água principal, em m; e $L t$ o comprimento do curso de água principal, em m;

- Declividade equivalente constante: a declividade equivalente constante descreve, também, o perfil do curso de água principal, considerando-se a declividade de cada trecho delimitado por duas curvas de nível, obtida por

$$
S_{3}=\left[\frac{\sum L i}{\sum\left(\frac{L i}{\sqrt{D i}}\right)}\right]^{2},
$$

em que $S_{3}$ é a declividade equivalente constante, em $\mathrm{m} \mathrm{m}^{-1} ; L i$ o comprimento do curso de água principal, entre duas curvas de nível subsequentes, em m; e $D i$ a declividade do curso de água principal, entre duas curvas de nível subsequentes, em m;

- Tempo de concentração: o tempo de concentração foi calculado por meio da equação de Kirpich, desenvolvida para bacias agrícolas do Tenessee (Pruski et al. 2004),

$$
t_{c}=57\left(\frac{L_{t}{ }^{3}}{H}\right)^{0,385}
$$

onde $t_{c}$ é o tempo de concentração da bacia hidrográfica, em minutos; $L_{t}$ o comprimento do talvegue, em $\mathrm{km}$; e $H$ a diferença de nível entre o ponto mais alto da bacia e o seu exutório, em $\mathrm{m}$.
Para a determinação da precipitação média, na bacia hidrográfica do Ribeirão Santa Bárbara, foram empregados dados de uma estação pluviométrica na bacia e outras quatro próximas, em bacias hidrográficas vizinhas, cujas denominações e respectivos códigos são: Fazenda Aliança, 1850001; Joviânia, 1749002; Ponte Sul Goiana, 1850000; Maurilândia, 1850003; e Ponte Meia Ponte, 1849016. As séries consistidas, disponíveis no sistema de informações da Agência Nacional de Águas, apresentam extensão de 31 a 34 anos de dados, entre 1971 e 2004.

A precipitação média anual na bacia foi obtida pelos métodos de Thiessen e das isoietas e pela combinação de ambos. Os polígonos de Thiessen e as isoietas da bacia hidrográfica do Ribeirão Santa Bárbara foram obtidos no SIG.

O método de Thiessen parte da determinação dos polígonos de Thiessen, que correspondem à área da bacia em que cada estação de medição exerce influência. Estes polígonos são delimitados geometricamente, sobre o mapa da bacia, pelas medianas às linhas que ligam duas estações vizinhas. A precipitação média é calculada pela média ponderada entre a precipitação de cada estação e o peso a ela atribuído, correspondendo à área de influência de cada estação.

As isoietas são linhas que representam a distribuição pluviométrica de uma região, através de curvas de igual precipitação. O cálculo da precipitação média, em uma bacia hidrográfica, pelo método das isoietas, consiste na ponderação das precipitações médias entre as duas isoietas que delimitam cada região, utilizandose, como fator peso, as suas respectivas áreas.

Tucci (2004) propôs um método para obtenção da precipitação média em uma bacia, que combina os dois métodos descritos anteriormente, por meio de um fator de ponderação que mescla os resultados dos polígonos de Thiessen e das isoietas.

Para a caracterização do regime hídrico na bacia e definição do ano hidrológico, foram utilizadas as precipitações médias mensais, correspondentes aos 27 anos de dados disponíveis para a estação Fazenda Aliança, obtidas pelo método de Thiessen. A estação foi escolhida por estar localizada na área da bacia hidrográfica do Ribeirão Santa Bárbara.

\section{RESULTADOS E DISCUSSÃO}

Por meio da sobreposição das cartas obtidas do IBGE, em escala 1:100.000, às imagens correspondentes, verificou-se ajuste satisfatório entre a carta 
e a imagem e que todos os cursos de água, inclusive os menores e as pequenas áreas de nascentes, são retratados na carta. Por se tratar de uma bacia de dimensões bastante reduzidas, a ausência de alguns cursos de água menores poderia trazer prejuízos à determinação correta das suas características físicas. Neste caso, seriam necessárias expedições a campo para se obter tais informações.

Os principais dados fisiográficos da bacia hidrográfica do Ribeirão Santa Bárbara estão apresentados na Tabela 1.

O coeficiente de compacidade $(K c)$ e o fator de forma $(K f)$, obtidos para a bacia hidrográfica do Ribeirão Santa Bárbara, indicam baixa tendência a enchentes. O mesmo é confirmado pela densidade de drenagem $(D d)$ observada, igual a $0,6 \mathrm{~km} \mathrm{~km}^{-2}$, considerada uma drenagem pobre. A densidade de drenagem pobre indica menor facilidade de escoamento até o exutório da bacia, retardando o pico da cheia. $\mathrm{O}$ valor de 1 indica a distância média que o escoamento superficial deve percorrer até alcançar o leito mais próximo, cerca de $450 \mathrm{~m}$. Indica, também, que a distância horizontal média entre dois cursos de água é de cerca de $900 \mathrm{~m}$.

A bacia do Ribeirão Santa Bárbara apresenta baixa declividade média, em torno de $0,4 \%$, o que, segundo o Sistema Brasileiro de Classificação de Solos (Embrapa 1999), caracteriza seu relevo como suave ondulado. Esta declividade, no entanto, não é uniforme em toda a bacia. Declividades mais acentuadas são percebidas na região de nascentes, que

Tabela 1. Características fisiográficas da bacia hidrográfica do Ribeirão Santa Bárbara, Goiás.

\begin{tabular}{lcr}
\hline \multicolumn{1}{c}{ Característica } & Unidade & Valor (R\$) \\
\hline Área & $\mathrm{km}^{2}$ & $1.371,16$ \\
Perímetro & $\mathrm{km}$ & 202,83 \\
Extensão da drenagem principal & $\mathrm{km}$ & 96,88 \\
Extensão do talvegue & $\mathrm{km}$ & 54,39 \\
Extensão total das drenagens & $\mathrm{km}$ & 762,84 \\
Altitude máxima do curso principal & $\mathrm{m}$ & 824,00 \\
Altitude mínima & $\mathrm{m}$ & 452,00 \\
Coeficiente de compacidade & - & 1,53 \\
Fator de forma & - & 0,46 \\
Densidade de drenagem & $\mathrm{km} \mathrm{km}{ }^{-2}$ & 0,60 \\
Extensão média do escoamento & $\mathrm{km}$ & 0,45 \\
Sinuosidade da drenagem principal & - & 1,78 \\
Declividade média da bacia & $\%$ & 0,40 \\
Elevação média & $\mathrm{m}$ & 637,21 \\
Declividade do álveo & $\%$ & 0,38 \\
Declividade equivalente constante & $\%$ & 0,27 \\
Tempo de concentração & $\mathrm{h}$ & 9,83 \\
\hline
\end{tabular}

é normalmente mais acidentada, tornando-se mais suaves com a proximidade da foz, conforme a curva hipsométrica (Figura 1).

A bacia do Ribeirão Santa Bárbara apresenta elevação máxima de $850 \mathrm{~m}$, na área de nascentes, e mínima, na foz, de $452 \mathrm{~m}$. A elevação média da bacia, em relação ao nível do mar, é de 637,21 m.

O Ribeirão Santa Bárbara pode ser considerado medianamente sinuoso e apresenta maior declividade na região de montante, a qual diminui em direção à foz. A declividade do álveo $\left(S_{l}\right)$, de $0,38 \%$, representa somente a diferença de nível entre a nascente e a foz, enquanto a declividade equivalente constante $\left(S_{3}\right)$, de $0,27 \%$, contempla a contribuição da declividade de cada trecho do rio, considerando-se as variações ao longo do perfil, e a declividade $S_{2}$, de $0,23 \%$, corresponde à área subentendida pelo perfil do curso de água. A primeira declividade está próxima ao valor de declividade média da bacia, enquanto as duas últimas estão mais próximas da declividade média do rio e demonstram que o Ribeirão Santa Bárbara tem baixa declividade. O perfil longitudinal do Ribeirão Santa Bárbara e as declividades $S_{1}, S_{2}$ e $S_{3}$ estão representados na Figura 2.

O tempo de concentração na bacia hidrográfica do Ribeirão Santa Bárbara equivale a, aproximadamente, $10 \mathrm{~h}$. O tempo de concentração elevado e o consequente pico de cheia reduzido refletem os aspectos já levantados, como a densidade de drenagem pobre, valores de $K c$ e $K f$ e a baixa declividade da bacia e do curso de água principal. Ao mesmo tempo em que indicam baixa tendência à ocorrência de enchentes, as características físicas da bacia hidrográfica do Ribeirão Santa Bárbara levam a crer, a despeito de outros fatores envolvidos, que a infiltração dos volumes precipitados no solo seja facilitada. Considerando-se somente estes aspectos, a bacia hidrográfica do Ribeirão Santa Bárbara está menos sujeita à ocorrência

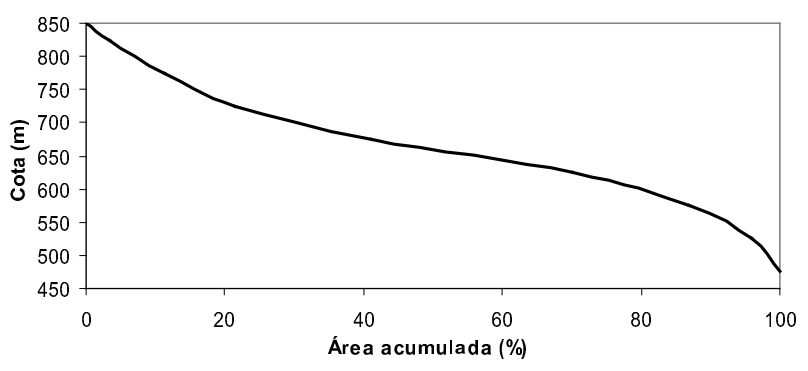

Figura 1. Curva hipsométrica da bacia do Ribeirão Santa Bárbara, Goiás. 


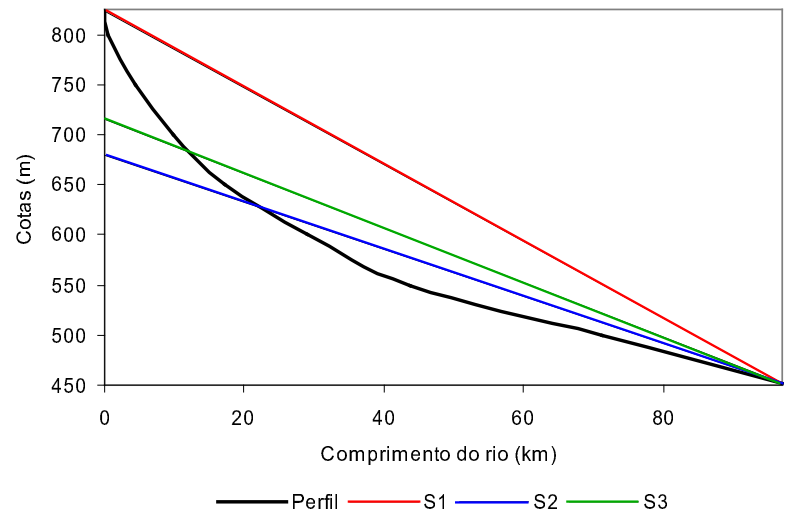

Figura 2. Perfil longitudinal e declividades do Ribeirão Santa Bárbara, Goiás.

de erosões e têm vazões de estiagem mais elevadas, devido ao armazenamento no solo.

As imagens da bacia hidrográfica do Ribeirão Santa Bárbara e visitas realizadas ao local permitem perceber que praticamente toda a sua área encontra-se modificada pela ocupação humana. Há poucos remanescentes de vegetação natural ao longo dos leitos de alguns cursos de água. As regiões de nascentes se encontram quase totalmente ocupadas. As principais atividades identificadas na bacia são a agricultura de diferentes cultivos anuais e as lavouras de canade-açúcar. Em alguns pontos, é possível perceber a existência de práticas de conservação do solo, como a construção de terraços.

A cobertura do solo afeta diretamente a capacidade de infiltração e o escoamento superficial do volume precipitado sobre a bacia e, por consequência, as suas vazões efluentes. Cardoso et al. (2006) concluíram que, em uma bacia com vegetação natural de floresta, os picos de vazão, nos períodos de alta pluviosidade, foram amenizados. Também, as vazões mínimas são amenizadas, na presença de boa cobertura vegetal na bacia, graças ao aumento da capacidade de infiltração e da recarga do aquífero que sustenta o escoamento, quando não há precipitação.

Os valores de precipitação média anual, na bacia do Ribeirão Santa Bárbara, obtidos a partir dos dados disponíveis nas cinco estações pluviométricas selecionadas, apresentaram pouca variação, com relação ao método de obtenção. A precipitação média obtida pelo método de Thiessen é de 1.510,1 mm, pelo método das isoietas é de $1.521,3 \mathrm{~mm}$ e pelo método que combina os dois anteriores é de 1.511,9 mm.

A distribuição da precipitação é desigual durante o ano e se caracteriza pela existência de verões

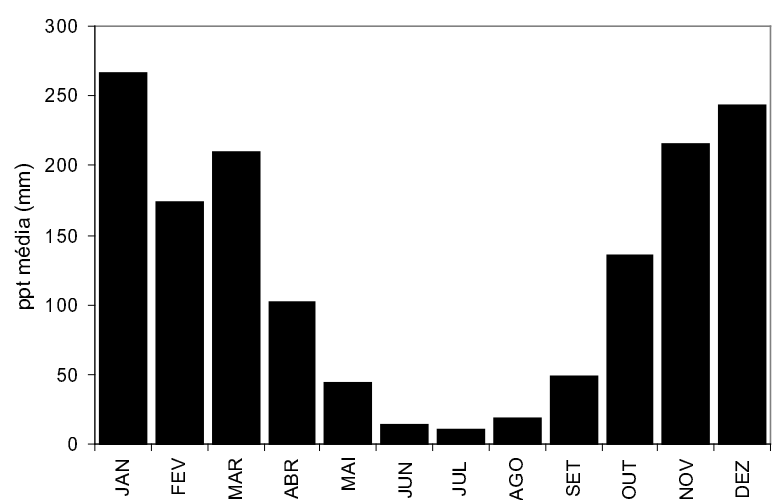

Figura 3. Precipitações médias mensais, na estação Fazenda Aliança, de 1972 a 2003, na bacia hidrográfica do Ribeirão Santa Bárbara, Goiás.

chuvosos e invernos secos, conforme precipitação média mensal ocorrida na estação Fazenda Aliança, localizada na bacia. $\mathrm{O}$ ano hidrológico estende-se de outubro a setembro, com precipitação quase inexistente nos meses de junho a agosto (Figura 3).

\section{CONCLUSÃO}

A bacia hidrográfica do Ribeirão Santa Bárbara constitui típica representante dos objetos de análise dos pleitos de outorga no Estado de Goiás: dimensões reduzidas, características fisiográficas que indicam baixa tendência a enchentes, ocupação essencialmente agrícola e poucos remanescentes de vegetação natural, com regime hídrico marcado por uma estação chuvosa e outra seca. O emprego do Sistema de Informações Geográficas (SIG), TNT mips (map image processing system), para o processamento de cartas na escala 1:100.000, e imagens geradas pelo satélite Landsat 7 mostram-se adequados à obtenção das características fisiográficas de bacias de dimensões reduzidas, por mostrar, até mesmo, pequenas nascentes e afluentes.

\section{REFERÊNCIAS}

BJERKLIE, D. M. et al. Estimating discharge in rivers using remotely sensed hydraulic information. Journal of Hydrology, Wellington, v. 309, n. 1-4, p. 191-209, 2005.

BRASIL. Lei federal $n^{\circ}$ 9.433, de 8 de janeiro de 1997: política nacional de recursos hídricos. Brasília, DF: ANA, 2002.

CARDOSO, C. A. et al. Caracterização hidroambiental da bacia hidrográfica do Rio Debossan, Nova Friburgo, RJ. Revista Árvore, Viçosa, v. 30, n. 2, p. 249-256, 2006. 
EMPRESA BRASILEIRA DE PESQUISA AGROPECUÁRIA (Embrapa). Centro Nacional de Pesquisa de Solos. Sistema brasileiro de classificação de solos. Rio de Janeiro: Embrapa, 1999.

MARTINS, O. C. Usos múltiplos da água na bacia hidrográfica do Rio dos Bois. 2003. Disponível em: $<$ http:// www.ucg.br/Institutos/nucleos/nupenge>. Acesso em: 21 jun. 2005.

NATIONAL AERONAUTICS AND SPACE ADMINISTRATION (NASA). Shuttle radar topography mission. 2000. Disponível em: $<$ http://www2.jpl.nasa.gov/ srtm/>. Acesso em: 02 dez. 2005.

PRUSKI, F. F.; BRANDÃO, V. S.; SILVA, D. D. Escoamento superficial. Viçosa: UFV, 2004.
SILVEIRA, G. L.; TUCCI, C. E. M.; SILVEIRA, A. L. L. Quantificação de vazão em pequenas bacias sem dados. Revista Brasileira de Recursos Hídricos, Porto Alegre, v. 3, n. 3, p. 111-131, 1998.

SVETLICHNYI, A. A.; SVETLICHNAYA, I. A. Spatial models of overland runoff formation. Water Resources, Moscou, v. 28, n. 4, p. 383-391, 2001.

TUCCI, C. E. M. Hidrologia: ciência e aplicação. 3. ed. Porto Alegre: UFRGS/ABRH, 2004.

VILLELA, S. M.; MATTOS, A. Hidrologia aplicada. São Paulo: McGraw-Hill do Brasil, 1975. 